\title{
Application of optogenetics-mediated motor cortex stimulation in the treatment of chronic neuropathic pain
}

\author{
Sufang Liu ${ }^{1,2}$ and Feng Tao ${ }^{1,3 *}$ \\ ${ }^{1}$ Department of Biomedical Sciences, Texas A\&M University Baylor College of Dentistry, Dallas, Texas, USA \\ ${ }^{2}$ Department of Physiology, Zhengzhou University School of Medicine, Zhengzhou, Henan, China \\ ${ }^{3}$ Center for Craniofacial Research and Diagnosis, Texas A\&M University Baylor College of Dentistry, Dallas, Texas, USA
}

\begin{abstract}
Motor cortex stimulation provides an alternate approach for intractable pain treatment. Optogenetic manipulation can produce gain- or loss-of-function in specific type of cells following light application. This state-of-the-art technology may be used in motor cortex stimulation to produce circuit-specific neuromodulation and regulate neuronal activities in motor cortex, thereby treating pain in the clinic. Here, we discuss the principle of optogenetics-mediated motor cortex stimulation and discuss its potential application in the treatment of chronic neuropathic pain.
\end{abstract}

\section{Introduction}

Motor cortex stimulation (MCS) has been used since 1991 to treat chronic neuropathic pain [1]. Electrical stimulation of the primary motor cortex has been demonstrated to suppress neuropathic pain in different animal models [2-6]. In the clinic, use of invasive electrical or non-invasive transcranial magnetic stimulation of primary motor cortex has been reported for alleviation of intractable chronic pain [7-11]. However, the mechanisms underlying the antinociceptive effect of MCS remain poorly understood. Moreover, most regions of the brain contain several subtypes of excitatory and inhibitory neurons. Activation or inhibition of each cell type would produce different functional responses, but MCS, while temporally precise, indiscriminately affects cellular elements throughout a volume of tissue. The ideal clinical neuromodulation tool would allow for restoration of physiologic neural activity in a selected pathologic circuit without affecting normal circuits.

\section{MCS-produced analgesia}

Previous studies have demonstrated that stimulation-produced analgesia is mediated by neuronal modulation in the central nervous system (CNS), including periaqueductal gray (PAG) [12-14]. MCS exerts pain treatment by modulating neuronal activities in the CNS. It has been suggested that PAG is one of the candidates which mediate the antinociception of MCS. In a human positron emission tomographic study, the increase in cerebral blood flow during MCS appears in several brain areas, including the midbrain [15]. Moreover, a longlasting increase in cerebral blood flow following MCS is observed in the PAG [16]. After MCS, the number of positive Fos-immunoreactive neurons increases in the PAG [3].

\section{Dopaminergic signaling in descending pain modulation}

Monoamines, including serotonin, norepinephrine, and dopamine, act via their different receptors to exert a complex modulation of neurotransmitter release from nociceptive afferents.
These monoaminergic systems play important roles in descending pain modulation [17]. They may exert either antinociceptive or pronociceptive effect according to the type of receptor involved and crosstalk between descending and local neurochemical signals [18]. The overall balance between inhibitory and excitatory supraspinal signals mediated by monoamines provides the basis for top-down modulation of pain sensation.

In the ventrolateral PAG, a group of dopaminergic neurons project to several brain areas, while some of them only have local projections within the PAG $[19,20]$. The sensory function, especially pain sensation, can be regulated after manipulating dopaminergic neurons in the PAG. Injection of apomorphine, a dopamine receptor agonist, into the ventrolateral PAG causes a robust antinociception, which is inhibited by the D2 receptor antagonist eticlopride but not the D1 receptor antagonist SCH-23390 [21]. However, D1, but not $\mathrm{D} 2$, receptor antagonism following infusions of dopaminergic ligands into the PAG attenuates opiate-induced analgesia in a dose-dependent manner [22]. These results suggest that PAG dopamine system plays an important role in pain modulation and different types of dopamine receptors may contribute to distinct pain signaling.

\section{Mechanism analysis of MCS-produced analgesia by optogenetics}

The recent development of optogenetics, a revolutionary research tool, combines the delivery of light of specific wavelengths (opto) with the introduction of genes encoding for light-sensitive transmembrane channels (genetics) and makes possible highly precise spatial and temporal control of specific neuronal populations [23]. Optogenetic neuromodulation has already proven its value to clinicians by providing

Correspondence to: Dr. Feng Tao, MD, PhD, Department of Biomedical Sciences, Texas A\&M University Baylor College of Dentistry, 3302 Gaston Avenue, Dallas, Texas 75246, USA; Tel: 1-214-828-8272; E-mail: tao@bcd.tamhsc.edu

Received: June 14, 2016; Accepted: July 07, 2016; Published: July 11, 2016 
novel insights into mechanisms of current clinical tools as well as circuit level disease pathophysiology. Optogenetics is uniquely useful in unraveling neuronal circuits in the CNS by enabling reversible gainor loss-of-function of discrete populations of neurons within restricted brain regions. This state-of-the-art technology can produce circuitspecific neuromodulation by overexpressing light-sensitive proteins (opsins) in particular cell types of interest. This is accomplished either by the use of viral vectors that infect only certain types of neurons through cell type-specific promoters, such as calcium/calmodulindependent protein kinase IIa, which will localize optogenetic proteins to excitatory neurons [24], or by targeted use of viral vectors that express their transgenes in a Cre-dependent manner [25] (Figure 1).

The most extensively used light-sensitive proteins are channelrhodopsins (e.g., channelrhodopsin-2), which are light-gated cation channels. These channels open when activated by blue light $(\sim 472 \mathrm{~nm})$ and are used to induce neuronal excitation. Oppositely, neuronal inhibition can be achieved via the expression of halorhodopsin (e.g., eNpHR3.0), a chloride pump activated by yellow light $(\sim 590$ $\mathrm{nm})[26,27]$. By expressing both proteins within the same neurons, it is possible for us to study the behavioral consequences of activating or inhibiting the same ensembles of neurons [27]. We may use Creinducible AAV-mediated light-sensitive protein overexpression in combination with mice that express Cre recombinase in different types of dopamine receptors under D1 or D2 promoter (D1-Cre and D2-Cre transgenic mice) [28] to investigate the effect of activation or inhibition of different dopaminergic neurons in the primary motor cortex on descending pain modulation.

\section{Conclusions}

Motor cortex stimulation (MCS) exerts pain treatment by modulating neuronal activities in the central nervous system. The emergence of optogenetics technology facilitates widespread applications for interrogation of complex neural networks, such as activation of specific neuronal pathways, previously found impossible with electrical stimulation. Consequently, optogenetic neuromodulation has led to findings of significant importance both during normal brain function as well as in different diseases. Future studies could utilize the novel technique to determine whether different dopaminergic neurons play distinct roles in MCS-induced descending pain modulation. Those studies will provide experimental evidence to demonstrate the role of endogenous dopamine system in MCSproduced analgesia.

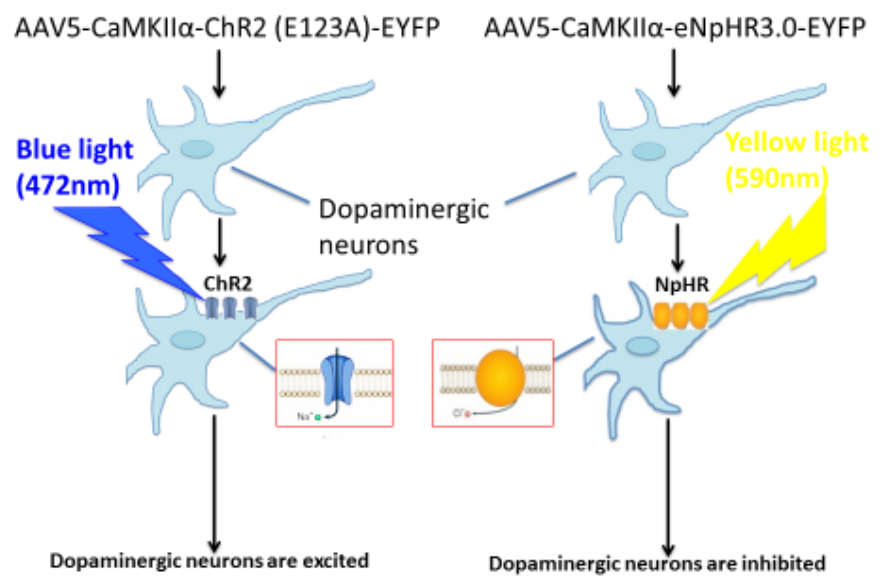

Figure 1. Circuit-specific neuromodulation.

\section{Acknowledgements}

This work was supported by the National Institute of Dental and Craniofacial Research Grants (R01 DE022880 and K02 DE023551).

\section{References}

1. Tsubokawa T, Katayama Y, Yamamoto T, Hirayama T, Koyama S (1991) Treatment of thalamic pain by chronic motor cortex stimulation. Pacing Clin Electrophysiol 14: 131-134. [Crossref]

2. Lucas JM, Ji Y, Masri R (2011) Motor cortex stimulation reduces hyperalgesia in an animal model of central pain. Pain 152: 1398-1407. [Crossref]

3. Pagano RL, Assis DV, Clara JA, Alves AS, Dale CS, et al. (2011) Transdural motor cortex stimulation reverses neuropathic pain in rats: a profile of neuronal activation. Eur J Pain 15: 268 e261-214. [Crossref]

4. Vaculin S, Franek M, Yamamotova A, Rokyta R (2008) Motor cortex stimulation in rats with chronic constriction injury. Exp Brain Res 185: 331-335. [Crossref]

5. Viisanen H, Pertovaara A (2010) Roles of the rostroventromedial medulla and the spina 5 -HT(1A) receptor in descending antinociception induced by motor cortex stimulation in the neuropathic rat. Neurosci Lett 476: 133-137. [Crossref]

6. Viisanen H, Pertovaara A (2010) Antinociception by motor cortex stimulation in the neuropathic rat: does the locus coeruleus play a role? Exp Brain Res 201: 283-296. [Crossref]

7. Fontaine D, Hamani C, Lozano A (2009) Efficacy and safety of motor cortex stimulation for chronic neuropathic pain: critical review of the literature. $J$ Neurosurg 110: 251-256. [Crossref]

8. Hosomi K, Saitoh Y, Kishima H, Oshino S, Hirata M, et al. (2008) Electrical stimulation of primary motor cortex within the central sulcus for intractable neuropathic pain. Clin Neurophysiol 119: 993-1001. [Crossref]

9. Lazorthes Y, Sol JC, Fowo S, Roux FE, Verdie JC (2007) Motor cortex stimulation for neuropathic pain. Acta Neurochir Suppl 97: 37-44. [Crossref]

10. Lefaucheur JP (2008) Use of repetitive transcranial magnetic stimulation in pain relief Expert Rev Neurother 8: 799-808. [Crossref]

11. Nguyen JP, Lefaucheur JP, Decq P, Uchiyama T, Carpentier A, et al. (1999) Chronic motor cortex stimulation in the treatment of central and neuropathic pain. Correlations between clinical, electrophysiological and anatomical data. Pain 82: 245-251. [Crossref]

12. Behbehani MM, Fields HL (1979) Evidence that an excitatory connection between the periaqueductal gray and nucleus raphe magnus mediates stimulation produced analgesia. Brain Res 170: 85-93. [Crossref]

13. Buckett WR (1981) Pharmacological studies on stimulation-produced analgesia in mice. Eur J Pharmacol 69: 281-290. [Crossref]

14. Mayer DJ, Liebeskind JC (1974) Pain reduction by focal electrical stimulation of the brain: an anatomical and behavioral analysis. Brain Res 68: 73-93. [Crossref]

15. Garcia-Larrea L, et al. (1999) Electrical stimulation of motor cortex for pain control: a combined PET-scan and electrophysiological study. Pain 83: 259-273. [Crossref]

16. Peyron R, Faillenot I, Mertens P, Laurent B, Garcia-Larrea L (2007) Motor cortex stimulation in neuropathic pain. Correlations between analgesic effect and hemodynamic changes in the brain. A PET study. Neuroimage 34: 310-321. [Crossref]

17. Ren K, Dubner R (2002) Descending modulation in persistent pain: an update. Pain 100: 1-6. [Crossref]

18. Millan MJ (2002) Descending control of pain. Prog Neurobiol 66: 355-474. [Crossref]

19. Dong HW, Swanson LW (2006) Projections from bed nuclei of the stria terminalis, anteromedial area: cerebral hemisphere integration of neuroendocrine, autonomic, and behavioral aspects of energy balance. J Comp Neurol 494: 142-178. [Crossref]

20. Hasue RH, Shammah-Lagnado SJ (2002) Origin of the dopaminergic innervation of the central extended amygdala and accumbens shell: a combined retrograde tracing and immunohistochemical study in the rat. J Comp Neurol 454: 15-33. [Crossref]

21. Meyer PJ, Morgan MM, Kozell LB, Ingram SL (2009) Contribution of dopamine receptors to periaqueductal gray-mediated antinociception. Psychopharmacology (Berl) 204: 531-540. [Crossref]

22. Flores JA, El Banoua F, Galan-Rodriguez B, Fernandez-Espejo E (2004) Opiate anti-nociception is attenuated following lesion of large dopamine neurons of the 
periaqueductal grey: critical role for D1 (not D2) dopamine receptors. Pain 110: 205214. [Crossref]

23. Kalanithi PS, Henderson JM (2012) Optogenetic neuromodulation. Int Rev Neurobio/ 107: 185-205. [Crossref]

24. Aravanis AM, Wang LP, Zhang F, Meltzer LA, Mogri MZ, et al. (2007) An optical neural interface: in vivo control of rodent motor cortex with integrated fiberoptic and optogenetic technology. J Neural Eng 4: S143-156. [Crossref]

25. Cardin JA, Carlén M, Meletis K, Knoblich U, Zhang F, et al. (2010) Targeted optogenetic stimulation and recording of neurons in vivo using cell-type-specific expression of Channelrhodopsin-2. Nat Protoc 5: 247-254.
26. Gradinaru V, Thompson KR, Zhang F, Mogri M, Kay K, et al. (2007) Targeting and readout strategies for fast optical neural control in vitro and in vivo. $J$ Neurosci 27 : 14231-14238. [Crossref]

27. Gradinaru V, Zhang F, Ramakrishnan C, Mattis J, Prakash R, et al. (2010) Molecular and cellular approaches for diversifying and extending optogenetics. Cell 141: 154165. [Crossref]

28. Lobo MK, Covington HE 3rd, Chaudhury D, Friedman AK, Sun H, et al. (2010) Cell type-specific loss of BDNF signaling mimics optogenetic control of cocaine reward. Science 330: 385-390. [Crossref]

Copyright: $(02016$ Liu S. This is an open-access article distributed under the terms of the Creative Commons Attribution License, which permits unrestricted use, distribution, and reproduction in any medium, provided the original author and source are credited. 